\title{
Review: electroconvulsive therapy reduces depressive symptoms
}

Efficacy and safety of electroconvulsive therapy in depressive disorders: a systematic review and meta-analysis. Lancet
2003;361:799-808.

\section{QUESTION: What are the benefits and harms of electroconvulsive therapy (ECT) in patients with depressive disorders?}

\section{Data sources}

Studies were identified by searching Biological Abstracts (1985 to September 2000), CINAHL (1982 to January 2001), EMBASE/Excerpta Medica (1980-2000), LILACS (1982 to January 2001), Medline (1966-2000), PsycINFO (1887-2000), SIGLE (1980-2000), and the Cochrane Library; and by reviewing reference lists and specialist textbooks.

\section{Study selection}

Randomised controlled trials (RCTs) were selected if they compared ECT with no ECT, ECT with pharmacotherapy, or different types of ECT in patients with depressive illness.

\section{Data extraction}

Reviewers independently extracted data on treatment comparisons, inclusion criteria, patient characteristics and co-treatment, and outcomes. Main outcome was change in symptoms on a continuous depressive symptom scale. Quality of RCTs was assessed on the basis of allocation concealment, masking, loss to follow up, and length of follow up.

\section{Main results}

73 RCTs met the selection criteria and were combined

Source of funding: UK Secretary of State for Health.

For correspondence: Professor J Geddes for the UK ECT Review Group, University of Oxford, Oxford, UK.

John.geddes@ psych.ox.ac.uk using a random effects model. ECT reduced depressive symptoms more than simulated ECT or pharmacotherapy (primary tricyclic antidepressants) (table). Bilateral electrode placement reduced depressive symptoms more than unilateral placement, and a higher dose of electrical stimulus was better than a lower dose (table). Frequency of treatment ( $1 v 3$ times/wk and $2 v 3$ times/ wk) and stimulus waveform (brief pulse $v$ sinewave) had no effect on depressive symptoms (table).

Electroconvulsive therapy (ECT) for depressive symptoms*

\begin{tabular}{|c|c|c|c|}
\hline Comparison & $\begin{array}{l}\text { Number of } \\
\text { trials }(n)\end{array}$ & $\begin{array}{l}\text { Standardised effect } \\
\text { size }(95 \% \mathrm{Cl})\end{array}$ & \\
\hline ECT $v$ simulated ECT & $6(n=256)$ & $-0.91(-1.27$ to -0.54$)$ & Favours ECT \\
\hline ECT $v$ pharmacotherapy & $13(n=760)$ & $-0.80(-1.29$ to -0.29$)$ & Favours ECT \\
\hline $\begin{array}{l}\text { Bilateral } v \text { unilateral } \\
\text { electrode placement }\end{array}$ & $22(n=1137)$ & $-0.32(-0.46$ to -0.19$)$ & Favours bilateral \\
\hline \multicolumn{4}{|l|}{ Frequency of ECT } \\
\hline $1 v 3$ times/week & $2(n=51)$ & $0.83(-0.39$ to 1.89$)$ & NS \\
\hline 2 v 3 times/week & $4(n=159)$ & $-0.30(-0.76$ to 0.20$)$ & NS \\
\hline $\begin{array}{l}\text { Higher } v \text { lower dose of } \\
\text { electrical stimulus }\end{array}$ & $6(n=337)$ & $0.58(0.33$ to 0.83$)$ & Favours higher dose \\
\hline $\begin{array}{l}\text { Brief pulse } v \text { sinewave } \\
\text { ECT }\end{array}$ & $5(n=181)$ & $0.62(-0.31$ to 1.54$)$ & NS \\
\hline
\end{tabular}

${ }^{*} \mathrm{NS}=$ not significant. $\mathrm{Cl}$ defined in glossary. Results based on meta-analysis using a random effects model. Length of follow up ranged from post-treatment to 8 months.

The effects of ECT on cognitive functioning were also reported. Results of the cognitive effects of ECT compared with pharmacotherapy were equivocal $(2$ trials). Patients treated with bilateral ECT had a longer time to recovery of orientation (6 trials), and greater impairment in retrograde (4 trials) and anterograde (7 trials) memory within 1 week than patients treated with unilateral ECT. More frequent ECT led to more cognitive impairment at the end of the treatment course (4 trials). Higher doses of ECT did not affect personal memory more than lower doses, but did result in some impairment of anterograde memory (5 trials).

\section{Conclusions}

ECT reduces depressive symptoms more than pharmacotherapy. Bilateral electrode placement is more effective than unilateral placement, and a higher dose is more effective than a lower dose.

\section{COMMENTARY}

Despite widely varying methods and quality that potentially contribute statistical noise to the meta-analyses, ECT was superior to sham ECT and to drug therapy with regard to the magnitude of symptom improvement in the review by the UK ECT group. This supports the use of ECT, a treatment for which the National Institute for Clinical Excellence guidelines take an overly conservative position. ${ }^{1}$ Regrettably, more efficacious forms of ECT (bilateral ECT and high dose ECT) are also associated with greater cognitive impairment.

The results of the comparison between ECT and drugs may not be applicable to newer antidepressant agents. The comparison also addressed only the magnitude of antidepressant response, not the speed of response, which is likely to be greater with ECT. Most patients require 6-9 ECT sessions, delivered across 2-3 weeks, to respond, whereas most require 4-6 weeks to respond to an antidepressant drug trial. ${ }^{2}$

The comparisons of more versus less frequent ECT and high versus low dose ECT also addressed only the magnitude of antidepressant response. Evidence also suggests that more frequent ECT ${ }^{3}$ and high dose $\mathrm{ECT}^{4}$ are each associated with a faster response. A faster response is important because it reduces suffering, risk of suicide, duration of hospital stay, and treatment costs and may hasten return to work.

Chittaranjan Andrade, MD National Institute of Mental Health and Neurosciences Bangalore, India

http://www.nice.org.uk/pdf/59ectfullguidance.pdf

American Psychiatric Association. The practice of electroconvulsive therapy: recommendations for practice, training, and privilegsive therapy: recommendations for practice, training, and privileging. Second

3 Shapira B, Tubi N, Drexler H, et al. Cost and benefit in the Shapira B, Tubi N, Drexler H, et al. Cost and benefit in the ECT. Br J Psychiatry 1998;1 172:44-8.

Sackeim HA, Prudic J, Devanand DP, et al. Effects of stimulus intensity and electrode placement on the efficacy and cogniintensity and electrode placement on the efficacy and cogni-
tive effects of electroconvulsive therapy. $N$ Engl I Med 1993:328:839-46. 